\section{HAEMORRHAGIC CORPUS LUTEUM MIMIC APPENDICITIS}

\section{Hasina Afroz ${ }^{1}$, Rabeya Akhter ${ }^{2}$, Shahela Jesmin ${ }^{3}$}

\begin{abstract}
:
Haemoperitoneum secondary to ruptured corpus luteum is a rare complication for women of reproductive life. The differential diagnosis of hemoperitoneum includes various types of acute abdomen that usually associated with acute lower abdominal pain and swelling lower abdomen. The differential diagnosis includes ruptured ectopic pregnancy, ruptured chocolate cyst, twisted ovarian tumor, pelvic inflammatory disease and pelvic peritonitis . Ruptured hemorrhagic corpus luteum is an uncommon cause of acute abdomem. Its occurrence is unknown but is likely quite frequent and without symptoms. Most cases are self limiting; enquire only observation with abdominal pain relieved with analgesics. Some need laparoscopy or laparotomy to achieve homeostasis if the patient is haemodynamically unstable.
\end{abstract}

Key word: Haemoperitoneum, Appendicitis, Ruptured Corpus luteum.

\section{Aim :}

The aim of this case report to reveal the presentation of hemorrhagic corpus luteum as acute abdomen which mimic acute appendicitis. Its clinical presentation, investigation, management with review of relevant literatures is discussed.

\section{Case-1:}

Mrs. Fatima, 25yrs old , she consulted with a surgeon for severe lower abdominal pain, nausea and vomiting. She is married for 2.5yrs Her LMP 15days back. She menstruates regularly \& never practices contraceptives. Clinical diagnosis: Acute appendicitis. Her blood report suggestive of acute appendicitis .Underwent urgent laparoscopy. After opening of abdomen, there was huge hemoperitoneum. Consulted with a gynecologist. Left ovary healthy, right ovary showed sign of recent rupture, contain yellowish tissue of corps luteum. Appendix was unremarkable. Her histopathology report was ruptured hemorrhagic corpus luteum.

\section{Case -2 :}

Mrs. Soma , 20 yrs old, she consulted with a surgeon for severe lower abdominal pain and nausea for 4 hours . She is married

1. Associate Professor, Dept. of Obst. \& Gynae, RMCH

2. Assistant Chief Medical Officer, Bangladesh Bank Medical Centre, Dhaka

3. Assistant Professor, Dept. of Obst. \& Gynae, RMCH for 14 months. Her LMP 15 days back. she took OCP for 1 year , changed to barrier method for 4 months. O/E: she was pale, anxious and restless but haemodynamically stable. Lower abdomen was severely tender. Clinical diagnosis was ascute appendicitis . Her Hb\% 10.7mgm/dl, TC 1070, TPC 187000, urine R/M/E-NAD, USG - enlarged left ovary $109 \mathrm{cc}(9.7 \mathrm{x} 8 \mathrm{~cm})$ , mild ascities, rt renal calculi, X-ray KUB region-NAD. Despite conservative treatment, there was no clinical improvement , Consulted with a gynaecologist, Cervical excitation test was positive and posterior fornix was full. Call for immediate laparotomy. There was huge haemopertitoneum, right ovary healthy, left ovary showed sign of recent rupture, contain yellowish tissue of corpus luteum. Appendix was unremarkable. Her histopathology report was ruptured hemorrhagic Corpus luteum.

\section{Case -3 :}

Jui a 14 yrs old unmarried regularly menstruating girl admitted in Rajshahi Medical College Hospital surgery ward on 14.04.09 with the complains of sever lower abdominal pain specially right iliac fossa for 4 hrs and diagnosed as a case of acute appendicitis. Then on examination she was haemedinamically stable and treated conservatively and discharged from hospital on 20.04.09 In spite of conservative treatment her symptom not relieved and on USG at 19.04.09. she was diagnosed as a case of right adenexal mass.

(Heterogeneous solid mass of size about 6.2 x $3.6 \mathrm{~cm}$ ) and her $\mathrm{Hb} \%$ - $11.8 \mathrm{gm} / \mathrm{dl}$, ESR- $32 \mathrm{~lm}$ in $1^{\mathrm{st}} \mathrm{hr}, \mathrm{TC}-\mathrm{N}-82 \%$, L- $14 \%$, E - $01 \%, \mathrm{M}-03 \%$ and as her symptom not relieved, repeat scan done on 28.04.09, shows right ovarian haemorrhagic cyst and significant amount of fluid collection in POD. Then she consulted with a gynecologist \& on examination she was haemodinamically stable but lower abdominal tenderness (++) , cervical excitation test was positive, posterior fornix was full. Then decision was taken for laparotomy. After opening the peritoneal cavity it was found that there is huge hemoperitoneum, left ovary is healthy, right ovary shows sign of recent rupture \& yellowish tissue of corpus luteum Appendix was unremarkable and no bleeding point present, then after peritoneal toileting and giving a drain tube, tissue from ruptured site taken for histopathology \& then incidental appendectomy done \& abdomen was closed in layers . Her histopathology report shows ruptured haemorrhagic corpus luteum.

\section{Discussion :}

Haemorrhagic corpus luteum is an ovarian cyst formed by bleeding into a corpus luteum cyst. If it ruptures, then 
haemoperitoneum results. As blood irritates the peritoneum, patient often presents with an acute onset of abdominal pain, usually in the second half of the menstrual cycle, 1, 2 other symptoms may include the following: vaginal bleeding, nausea and /or vomiting, weakness, syncope, shoulder tenderness, circulatory collapse ${ }^{1}$. Physical findings can range from mild unilateral lower abdominal tenderness to those of an acute abdomen with severe tenderness. O/E muscle guarding, rebound tenderness, ${ }^{1}$ an adenexal mass may be palpable. Orthostatic changes are consistent with amount of hemorrhage. Change in hematocrit value (serially, if necessary) indicate continued bleeding, pregnancy test (to exclude ectopic pregnancy), total count of WBC (to exclude appendicitis) ${ }^{2}$, pelvic ultrasonography, abdominal CT scan (to determine the amount of abdominal bleeding) and coagulation profile (to exclude bleeding disorder) may be requested Culdocentesis usually no longer involved when ultrasonography is available.

Bleeding is often minor but may be more serious in women on anticoagulants, with a bleeding disorder, coagulation failure or women with abnormal follicle maturation ${ }^{3}$. the real incidence both of cyst formation and of rupture is unknown, as cases may not always come to medical attention. The condition most commonly occurs in women aged 18- 35 years. Haemoperitoneum described in a series of women aged 12- 52 years taking warfarin therapy ${ }^{3,5}$, coagulopathy secondary to cirrhosis of the liver, thrombocytopenia, continuous ambulatory haemodialysis ${ }^{3}$.

Haemoperitoneum are less frequent in women with milder defects of homeostasis, but have been described in woman with mild type-2 VWD, carrier of hemophilia B, combined defect of VWD and a storage pool disorder ${ }^{3}$. Bleeding disorders also causes menorrhagia when there is a defect of haemostasis, there are a number of potential mechanism for hemoperitoneum. Bleeding may occur at the time of ovulation when the ovum is extruded from the follicle or from subsequent rupture of a hemorrhagic ovarian cyst. Less frequently bleeding may occur into the broad ligament of the uterus causing a retroperitoneal haematoma. In the majority of cases, no risk factor for bleeding was identified. However, episodes of mid- cycle bleeding are probably triggered by ovulation or related ovarian cyst formation ${ }^{3}$.

The priorities in management are effective fluid resuscitation and to secure haemostasis. In the past, a surgical approach has been the primary intervention. Laparotomy resulting in lutectomy, wedge excision or oophorectomy ${ }^{5}$.

Modern management of hemoperitoneum includes effective transfusion of blood and blood product may avoid surgical intervention even in women with bleeding disorders ${ }^{3}$. This approach conserves ovarian function and women conceive successfully ${ }^{3}$. The nature of conservative management will depend on underlying disease, optimum management necessitates close liasson between a haematologist experienced in managing bleeding disorders and the gynaecological or obstetric team.

\section{Conclusion:}

It is important to be aware of this possibility when assessing an acute abdomen in a pre-menopausal woman, particularly if she is on mid-cycle without any ovulation suppression. As this is not a pathological condition, ovary is not transplantable, ovarian function is not replaceable, try to avoid laparoscopy and manage the patient conservatively. As hemoperitoneum frequently occurs in young women early in their reproductive life, conservation of fertility and the hormonal benefit of normal ovarian function should be a primary concern.

\section{Reference:}

1. Michael M Frumovitz. M.D. Charles J Ascher - Walsh, M.D Corpus Luteum Rupture: Medicine, last update: Sep 7, 2006.

2. Oshri Barel, M.D, Noam Smorgick, M.D. M.S.c Moti Pansky, M.D.D David Schneider, M.D. and Reuvitt Halperin , M.D. Ph.D Clinical and laboratory Presentation of Hemorrhagic Corpus Luteum Journal of gynaecologic surgery; vol 24: no 1; 2008.

3. Payne JH, Maclean RM, Hampton KK, Baxter AJ and Makris M. Haemoperitoneum associated with ovulation in women with bleeding disorders : the case for conservative management and the role of the contraceptive pill, Sheffiel Hemophilia and Thrombosis Centre, Royal Hallamshire Hospital .Glossop Road, Sheffiel S102 JF, UK. Tel : +44(0)1142712500: Fax : +44(0) 1142756126 : e-mail ; m.makris@sheffield.ac.uk

4. Ginsberg JS, Hirsh J: Use of antithrombotic agents during prengnancy: Ches at 1005; 1008: 505s-511s.

5. Tarim A, Yildirim S, Nursal TZ, Noyan T,: Intraabdominal and intramural hemorrhage due to warfarin therapy ; Baskent Universitesi Genel Crrahi ANabilim Dali, Turkey . eatarim@hotmail.com.

6. Hallatt JG Steele CH Jr, Snyder M. Ruptured corpus luteum with hemoperitoneum ; a study of 173 surgical cases. Am J obstet Gynecol. 